une revue Gallia

Rhône-Alpes | 2008

\title{
Saint-Vulbas
}

Marcillieux rue Philibert-Le-Beau

\section{Cécile Ramponi}

\section{(2) OpenEdition}

12 Journals

Édition électronique

URL : http://journals.openedition.org/adlfi/1540

ISSN : 2114-0502

Éditeur

Ministère de la culture

Référence électronique

Cécile Ramponi, "Saint-Vulbas », ADLFI. Archéologie de la France - Informations [En ligne], Rhône-Alpes, mis en ligne le 01 mars 2008, consulté le 03 mai 2019. URL : http://journals.openedition.org/ adlfi/1540

Ce document a été généré automatiquement le 3 mai 2019.

(c) Ministère de la Culture et de la Communication, CNRS 


\title{
Saint-Vulbas
}

\author{
Marcillieux rue Philibert-Le-Beau
}

\section{Cécile Ramponi}

\section{Identifiant de l'opération archéologique : 9923}

Date de l'opération : 2008 (EX)

1 Des sondages ont révélé des vestiges de la période gallo-romaine, comme le laissait supposer la carte archéologique : 3 des 58 sondages ouverts ont permis d'observer des restes de construction et de démolition d'un petit établissement rural antique, caractérisé par la présence de tuiles, d'un peu de mobilier céramique et de quelques maçonneries.

2 Les vestiges se situent dans la partie médiane de la parcelle, endroit où les recouvrements limoneux sont les plus importants entre la plaine fluvio-glaciaire et la butte morainique située à l'est de la parcelle. Deux secteurs d'implantations ont été retrouvés, l'un en bordure nord de la parcelle et l'autre en bordure sud, séparés de seulement $60 \mathrm{~m}$. Du mobilier céramique gallo-romain mis au jour dans un sondage intermédiaire laisse penser que l'occupation ne se limite pas à ces deux pôles.

Dans la partie nord du terrain, plusieurs restes de maçonneries sur solin de galets liés au mortier, laissent imaginer au moins un bâtiment. Les coupes indiquent des creusements dans le terrain naturel, probablement pour ménager des terrasses et asseoir les constructions. La nature et la forme du bâtiment ne sont pas définies, mais l'ensemble présente un caractère rural. On pourrait certainement le comparer aux établissements ruraux antiques retrouvés dans l'Ain (De Klijn, Motte, Vicherd 1996).

4 Dans la partie sud de la parcelle, c'est un épandage de tuiles, limité par une grosse pierre, qui a été retrouvé. La présence de cette pierre et l'arrêt brutal des démolitions pourrait faire penser à un aménagement, malgré l'absence de maçonneries et de négatifs de poteaux ou de solins. On peut à ce titre proposer de le rapprocher des constructions de type « fonds de cabane », retrouvées dans la plaine de l'Est lyonnais (Coquidé, Frascone, Ramponi, Thollon-Pommerol, à paraitre). 
5 La période d'installation déduite par le mobilier retrouvé lors du nettoyage des démolitions et des coupes, s'étend sur plusieurs siècles, du $\mathrm{I}^{\mathrm{er}} \mathrm{s}$. au $\mathrm{IV}^{\mathrm{e}} \mathrm{s}$. de notre ère. Seuls les vestiges de la partie sud pourraient n'avoir pas dépassé le second siècle. De simples sondages ne permettent toutefois pas de déceler d'évolution ou de réorganisation dans les installations.

6 Cécile Ramponi

INDEX

Index chronologique : Antiquité romaine

Thèmes : fond de cabane, habitat rural, tuile

Index géographique : Rhône-Alpes, Ain (01), Saint-Vulbas

operation Expertise (EX)

\section{AUTEUR}

CÉCILE RAMPONI

INRAP 